\title{
Do Legal Standards Affect Ethical Concerns of Consumers?
}

\author{
Dirk Engelmann* \\ Dorothea Kübler**
}

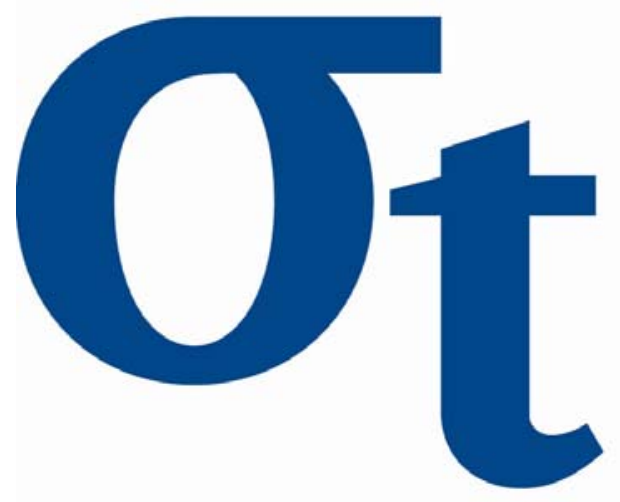

* Royal Holloway University of London, United Kingdom ** Technische Universität Berlin, Germany

This research was supported by the Deutsche Forschungsgemeinschaft through the SFB 649 "Economic Risk". 


\title{
Do Legal Standards Affect Ethical Concerns of Consumers? *
}

\author{
Dirk Engelmann ${ }^{\dagger} \quad$ Dorothea Kübler ${ }^{\ddagger}$
}

January 15, 2008

\begin{abstract}
In order to address the impact of regulation on ethical concerns of consumers, we study the effect of a minimum wage. In our experimental market, consumers have monopsony power, firms engage in Bertrand competition, and workers are passive recipients of a wage payment. Two treatments are employed, one with no minimum wage in the first part but with a minimum wage in the second part, and one treatment with a minimum wage at the outset that is abolished in the second part. In both treatments, wages decrease over time in the first part even though some consumers show an interest in fair wages. If a minimum wage is in place, wages decline even faster. Introducing a minimum wage in a mature market raises average wages, while abolishing it lowers them. We discuss the implications of our results, such as the crowding out of ethical behavior through legal regulation.

Keywords: Fairness, Crowding Out, Consumer Behavior, Minimum Wage, Experimental Economics
\end{abstract}

JEL-Classification: C91, J88, K31

${ }^{*}$ We thank Dana Novotny and Julia Schmid for help with conducting the experiment as well as Georg Weizsäcker, Richard McAdams and participants at the 2005 GEW meeting in Cologne and the LSA Meeting 2007 in Berlin for helpful comments and suggestions. This research was supported by Deutsche Forschungsgemeinschaft through SFB 649 'Economic Risk'.

${ }^{\dagger}$ Royal Holloway, University of London, Department of Economics, Egham, Surrey, TW20 0EX, United Kingdom, e-mail: dirk.engelmann@rhul.ac.uk.

${ }^{\ddagger}$ Department of Economics and Management, Technical University Berlin and IZA, Bonn. Address: H 50, Straße des 17. Juni 135, D-10623 Berlin, Germany, e-mail: d.kuebler@ww.tu-berlin.de 


\section{Introduction}

In the last decades, firm policy with regard to worker protection, climate change, or other environmental issues has received a lot of attention from the public. Firms can profit from fair behavior towards the workers or from environment-friendly production technologies if a sufficient number of consumers is willing to pay a higher price for its products than for products of other firms. Acting according to the consumers' views of proper conduct allows a firm to gain a reputation for being ethical. Thus, it is possible that fair behavior survives in a market environment. However, this depends crucially on the preferences of consumers.

Consumers' willingness to pay for ethical behavior of firms expresses itself not only in choosing to buy from firms that satisfy higher standards at higher prices, but also in agreeing to legal regulations that are likely to result in higher prices. Freeman (1996), for example, reports on an ABC/Washington Post poll from 1989 which posed two questions to the public. First, it asked whether the respondent's salary or the salary of someone in the immediate family would go up if the government increases the federal minimum wage in the US. Responses were as follows: Only in $8 \%$ of the cases the chief wage earner's salary would go up, in $12 \%$ of the cases someone else in the family's salary would go up, and in $79 \%$ the salary of no-one in the family would go up. The same respondents were then asked whether they would still favor raising the minimum wage if business passed the increased salary costs on to the consumer in the form of higher prices. To this question, $82 \%$ answered with yes while only $16 \%$ said no. The fact that the vast majority of consumers accepts higher prices because of a raise in the minimum wage is striking as it suggests substantial willingness to pay for fair treatment of third parties. On the other hand, this was a hypothetical question, 
and it might well be that words are not followed by deeds. We use an experiment with real monetary incentives to study consumers' willingness to pay for proper firm conduct in a controlled environment.

The main issue addressed by our experiment is whether regulation can undermine consumers' willingness to pay for ethical firm behavior. Often governments want to ensure certain standards of behavior by legal regulations, such as minimum wages. The effects of such interventions on consumer behavior can be ambiguous. Apart from the direct effect of the regulation, e.g. forcing firms to pay a certain minimum wage, two other effects must be considered. On the one hand, if the regulation requires a certain level of ethical behavior, the reputation gain for firms from adhering to these (or stricter) principles of fairness might be small. As a result, if the regulation can enforce ethical behavior only to a limited extent, the level of ethical behavior might be lower than without the regulation. On the other hand, the intervention by the government might send a signal that ethical conduct is important and thus make consumers more aware and willing to hold firms to high standards. As a result, the regulation could also increase the benefits that a firm obtains from a reputation for ethical behavior. Therefore, the regulation could actually lead consumers to enforce fair firm behavior above the level prescribed by the regulation. Our experiment provides evidence on the relative impact of these effects.

We study a specific example, namely the issue of fair wages in a laboratory experiment. ${ }^{1}$ Some consumers may be willing to pay higher prices if they know that the firm pays its workers a fair wage. As discussed above, implementing a minimum wage that firms have

\footnotetext{
${ }^{1}$ The main reason for studying fair wages is that other questions of ethical firm behavior such as environmentally friendly production are very hard if not impossible to implement in a laboratory experiment.
} 
to pay their workers can have three effects. In addition to the direct effect of a binding minimum wage, there two indirect effects. On the one hand, a minimum wage might undermine the reputational gain of a firm from paying workers a fair wage and as a result lead to lower wages. On the other hand, it might signal to consumers that market wages are too low. Hence, consumers will pay more attention to wages paid by firms and possibly condition their purchase decision on them.

In the experiment, we use a simple setup to study the relationship between fairness and regulation. Consumers have monopsony power in a Bertrand duopoly market. Workers have no bargaining power at all as they have no decision to take. They are employed by a firm and can neither be fired nor can they quit themselves. Their only source of income is the wage. In each duopolistic market, the consumer is informed about the prices and wages of both firms. He can then decide which firm to buy from, and he can also split his demand between firms. This gives the consumer the power to enforce higher wages by buying from the firm with the higher wage.

We compare two treatments. In the first, there is no minimum wage initially, but it is introduced after the first half of the experiment. In the second treatment, there is a minimum wage at the beginning, but it is abolished after the first half of the experiment. This allows us to study the effect of a minimum wage at different stages of experience in a market, and the effect of changes in the minimum wage policy.

We find a significant difference between wages with and without a minimum wage in the first part of the experiment. In both treatments, wages start at a similar level and decline over time. However, in the treatment with a minimum wage, wages initially (in the first five periods) decline faster than in the treatment without a minimum wage. Consumer 
behavior is also different: Without a minimum wage, consumers frequently buy from the firm with the higher price if this firm also pays the higher wage. This never happens in the treatment with a minimum wage. Hence we do find a substantial willingness to pay for a better treatment of workers, as suggested in the questionnaire study by Freeman (1996), but we also find that this is completely undermined by the minimum wage, even though the minimum wage is at a very low level.

In the second part of the experiment, things are different. Introducing a minimum wage later in the experiment does not harm workers on average and helps some of them. Those consumers who buy from firms with higher wages tend to continue to do so, while the minimum wage becomes binding in other markets where wages have already fallen below that level. By contrast, abolishing the minimum wage leads to a further decline in wages. In both treatments, there is a lot of heterogeneity in behavior. Some consumers enforce equitable wages while others buy purely according to price with no regard to the wages. As a result, price and wage dynamics differ substantially among groups.

Our results support crowding out of fairness concerns, in particular if the minimum wage is introduced at the start of the market interaction. We also find evidence, however, for the minimum wage to become binding and hence to increase wages. Moreover, it can help to establish a standard for fair wages above the minimum wage in markets where consumers have already experienced a situation without a minimum wage. This last finding suggests that the economic policy of introducing a minimum wage not only changes the set of actions but also the perceptions of fairness in a market.

Experimental evidence has shown repeatedly that many people's choices cannot be reconciled with purely selfish preferences. In the dictator game (e.g. Forsythe, Horowitz, 
Savin and Sefton 1994, Roth 1995) proposers often allocate positive amounts of money to another player which is in line with other-regarding preferences. In the light of this literature it is not unexpected that consumers care about the wage of the worker.

The game used here is more closely related to the three-person ultimatum game by Güth and van Damme (1998) where the proposer can allocate money to a responder and to a dummy. The responder can accept or reject the proposal and the dummy is passive although his payoff depends on the actions of the other players. Experimental tests of this game show that the responder earns more than the dummy on average, see Güth and van Damme (1998) and Güth, Schmidt and Sutter (2007). This suggests that the responders' willingness to punish proposers for the sake of the dummy player is limited. On the other hand, in a third-party punishment game (Fehr and Fischbacher, 2004), where a third player can punish the dictator in a two-person dictator game after he has made the choice, unequal splits are frequently punished and dictators frequently split the pie equally. In our experiment, since a consumer can choose between two firms he can use competition between them to play them off against each other. In contrast to the threeperson ultimatum game and the third-party punishment game, he can punish an unfair firm by switching to the less unfair firm. This makes punishment quite effective and could thus lead to a strong impact of consumers' fairness concerns. ${ }^{2}$

There is a growing literature on crowding out of intrinsic motivation with extrinsic

\footnotetext{
${ }^{2}$ All these experiments find evidence for an indirectly reciprocal motivation of participants, because they reward or punish friendly or unfriendly acts between two other participants, that do not affect them directly. See, for example, Nowak and Sigmund (1998), Seinen and Schram (2006), and Engelmann and Fischbacher (2003) for the literature on indirect reciprocity.
} 
or economic incentives. ${ }^{3}$ A recent publication studying the interaction between intrinsic motivation and formal rules is Falk and Kosfeld (2006). They examine the impact of the principal's choice to restrict the possible choices of the agent on the effort level of the agent. They find that the intention of the principal matters, i.e. the crowding-out effect of restricting the agent's choice set critically depends on the principal actually taking this choice instead of an exogenous change in the choice set. By contrast, the minimum wage in our experiment is introduced or abolished exogenously, i.e. by the experimenter, but we find that it can nevertheless affect behavior adversely.

There is little experimental work on the effects of minimum wages yet. A notable exception is the study by Falk, Fehr and Zehnder (2006) which focuses on the impact of a minimum wage on the reservation wage of workers and on their fairness perceptions. Brandts and Charness (2004) investigate the effect of a minimum wage in a labor market characterized by gift exchange between workers and employers. Note that in contrast to these two studies, we focus on the consumers' reaction to a minimum wage, not the workers'.

A large portion of the empirical literature on minimum wages investigates the employment effect of raising the minimum wage. This has been rather controversial (Card 1992, Card and Krueger 1994, Dickens, Machin, and Manning 1999). In our experimental design, employment is exogenously fixed to keep the question of what a fair wage is simple for the consumers. Empirical studies on the minimum wage have also observed so-called spillover effects. An increase in the minimum wage has been found to increase wages by more than the required amount (Card and Krueger 1995, Katz and Krueger 1992). We can study this

\footnotetext{
${ }^{3}$ See Frey (1997), Frey and Jegen (2001), Gneezy and Rustichini (2000a) and (2000b). See also Ostrom (2000) for a discussion.
} 
issue with our experimental data and indeed observe that consumers and firms are willing to pay more than the minimum wage under certain conditions.

The rest of the paper is structured as follows. Section 2 describes the design in detail. In Section 3 we present and analyze the results. Section 4 concludes.

\section{Experimental Design}

We study a simple duopoly market. There is one consumer, who can buy up to 10 units of a fictitious homogeneous good. Each unit has a value of 25 points for the consumer. There are two firms, each represented by a manager who takes the decisions for the firm. ${ }^{4}$ Each firm employs one worker. This worker is an actual participant in the experiment, even though he has no choice to make. The firm can produce up to 10 units of the good. The firm chooses a price (per unit) $p \in[0,50]$ and a wage $w$ (per unit). If no minimum wage is in place, then $w \in[0,50]$, otherwise $w \in[3,50]$, that is the minimum wage is 3 if it is in place. The firm cannot price discriminate, i.e., the same price-wage combination holds for all 10 units, and the firms do not have an option to restrict supply. Wages are paid only for units actually sold and there are no other costs. Workers have no costs, no other source of income than the wage, and no outside option. If a consumer buys a unit from a firm that has chosen price $p$ and wage $w$, the consumer earns $25-p$ for this unit, the firm makes a profit of $p-w$ and the worker earns $w$. These earnings are multiplied by the purchased number of units in order to compute total earnings in a period.

\footnotetext{
${ }^{4}$ In the following, we refer to the manager as the "firm" since he is the player acting on behalf of it.
} 
The timing of the game is as follows. After the firms have made their choices, the consumer is informed about both firms' price-wage pairs $\left(p_{1}, w_{1}\right)$ and $\left(p_{2}, w_{2}\right)$. He then decides how many units to buy from the firms. The consumer can buy any combination of integer amounts from the two firms up to a total quantity of 10, and he can also buy no units at all. At the end of each period all participants in the group are informed about all decisions in the group, i.e., about both firms' price-wage combinations and about the decision of the consumer.

In the subgame-perfect Nash-equilibrium of the stage game with selfish agents, firms set $w=0$ if there is no minimum wage and $w=3$ if there is a minium wage. The equilibrium price is $p=w$ or $p=w+1$ (with $p_{1}=p_{2}$ ) and the consumer always buys 10 units from the cheaper firm as long as $\min \left(p_{1}, p_{2}\right)<25$ for this firm, buys nothing if $\min \left(p_{1}, p_{2}\right)>25$ for both firms and an arbitrary quantity if $\min \left(p_{1}, p_{2}\right)=25$. If both firms choose the same price, in equilibrium the consumer can split his demand in an arbitrary way between the two firms. Hence, in equilibrium almost the whole surplus goes to the consumer. ${ }^{5}$ By contrast, the payoffs are split equally among all five market participants if both firms choose $p=20$, $w=10$ and the consumer buys 5 units from each of the firms. In this case the payoff for all participants is $\pi=10 * 5=50$. Hence the minimum wage is substantially below the wage that would ensure equal payoffs.

Note that as long as the consumer buys 10 units, the total earnings in the market are constant. How a consumer spreads his purchases across the two firms does not affect the

\footnotetext{
${ }^{5}$ As the stage game has two equilibria with $p=w$ or $p=w+1$, collusive equilibria exist due to the possibility to punish deviations. While our main focus is on wages, we note that we do not find evidence of collusive firm behavior since most of the surplus does in fact go to the consumers (see below).
} 
total earnings. This has the appealing property that we can study consumers' concerns for fairness that are not confounded with concerns for efficiency. ${ }^{6}$

Details of the implementation are as follows. We use a fixed-matching protocol, that is a group of five participants (one consumer and two firm-worker pairs) stays together for the whole course of the experiment. The main motivation for fixed groups is that we are interested in the degree to which consumer behavior drives firm behavior. This is obviously more relevant if the firms meet the same consumers many times. Participants keep their role for the whole experiment in order to enhance the possible inequalities and fairness concerns. The experiment lasts for 40 periods.

An interesting aspect of our setting is that consumers do not have an incentive to signal that they care about fairness if in fact they do not. This is in contrast to many other experiments that try to assess the fairness concerns of players such as ultimatum, trust and gift-exchange games. In these games, signalling typically increases the extent of fair behavior in early periods of repeated games. In our experiment, since higher wages translate at least to some degree into higher prices, selfish consumers want to signal that they do not care about the worker but only about low prices.

We conducted two treatments. In treatment NMF (No Minimum wage First), there is initially no minimum wage, but it is introduced after the first 20 periods. In treatment MF (Minimum wage First), there is initially a minimum wage in place, but it is abolished

\footnotetext{
${ }^{6}$ See Kritikos and Bolle (2001), Charness and Rabin (2002), Engelmann and Strobel (2004), and Harrison and Johnson (2006) for evidence that experimental subjects frequently exhibit preferences to maximize the total payoff. These papers show that the interpretation of many experimental results as evidence for fairness concerns is problematic since fairness concerns are frequently confounded with concerns for efficiency.
} 
after 20 periods. At the beginning of the experiment, the participants are informed that there will be a change in the rules after 20 periods without mentioning that this change concerns the minimum wage. They are also informed that the group composition and the role assignment will not be changed. We implemented a market frame, that is in the instructions (for the full text see the Appendix), participants are called consumers, firms and workers and we use the terms "prices" and "wages". The minimum wage is introduced as follows. In treatment MF, it is stated that the wage has to equal at least 3. After the first 20 periods, participants in treatment NMF are informed that from now on the wage has to be at least 3, and in treatment MF instructions specify that the wage only has to be non-negative.

For each treatment, we ran five sessions with two groups of five participants each. Hence we have ten independent observations per treatment and a total of 100 subjects ( 40 of which are workers who do not take any decisions). The experiments were conducted in a computer lab at Technical University Berlin in December 2004 and February 2005. The experimental software was programmed and the experiment was run using z-Tree (Fischbacher, 2007). At the end of the experiments, earnings in points where converted at a rate of 200 points $=1$ Euro and were paid in cash immediately after the experiment. Participants received 5 Euro in points as an initial endowment. This serves to cover possible losses (if firms sell below the wage or consumers buy for a price above their valuation) and to ensure that workers get at least some non-trivial compensation. ${ }^{7}$ The sessions took between 60 and

\footnotetext{
${ }^{7}$ Paying the workers a higher initial endowment was not feasible, because it would obviously have changed the egalitarian price-wage combination and more importantly would have reduced any fairness motivation to pay them a higher wage. We did observe some participants in the worker role who were clearly unhappy
} 


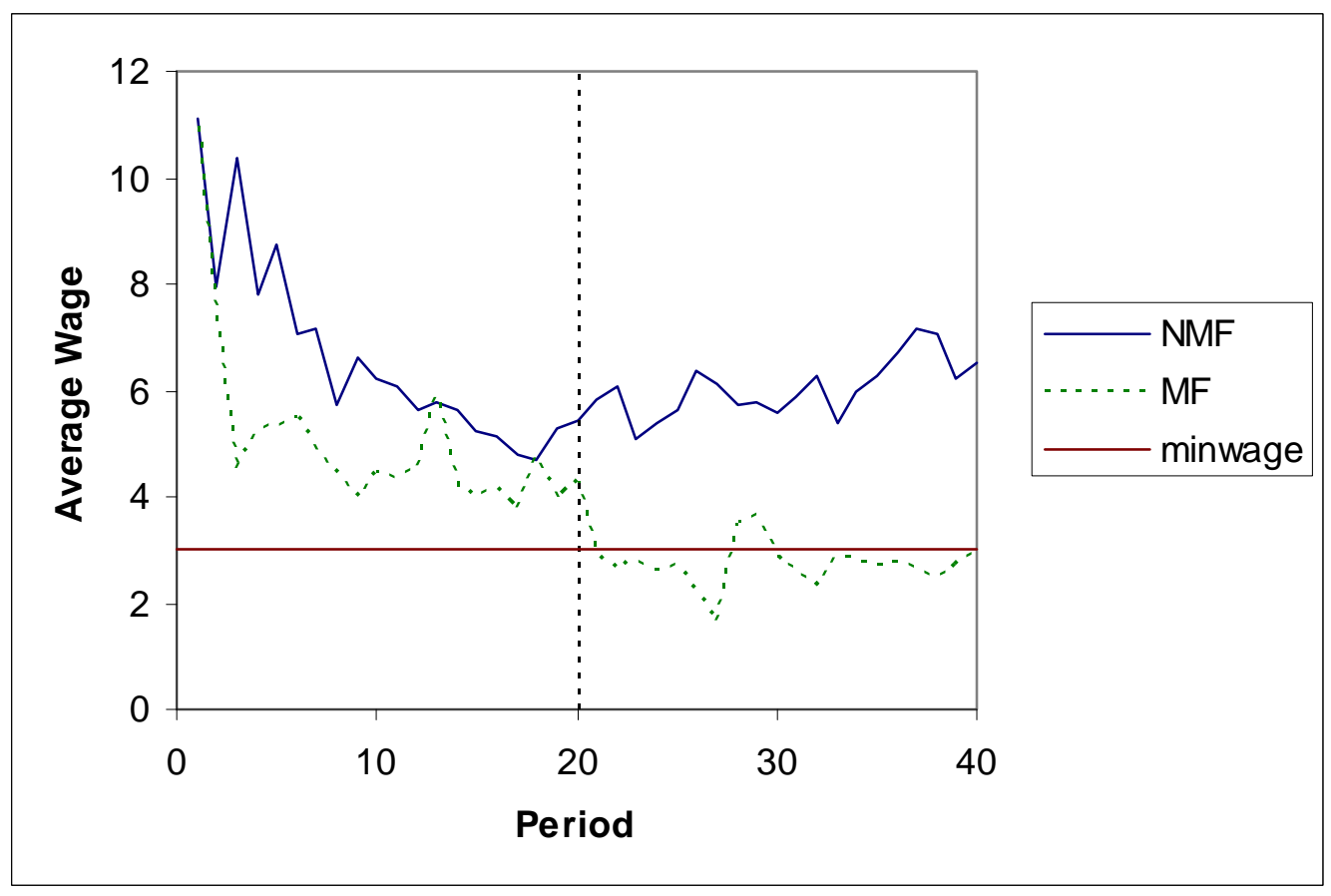

Figure 1: Average wages over time

70 minutes and average earnings were 14.31 Euro in Treatment NMF and 14.65 Euro in Treatment MF (including the initial endowment). ${ }^{8}$

with the fact that they had no choice to make and also earned only marginally more than their initial endowment. This, however, was a necessary consequence of translating the situation of powerless workers into a laboratory setting.

${ }^{8}$ If the consumers buy ten units (all other decisions determine only the distribution among players), the average payoffs are 10 Euro plus 5 Euro initial capital. The slightly lower earnings that we observe result from consumers occasionally buying fewer than 10 units. 


\section{Results}

\subsection{Wages}

Our main results are summarized in Figure 1, which shows the development of average wage offers in the two treatments across time. The wages reported here are those set by the firms, not only the wages that were actually paid. ${ }^{9}$ Average wage offers start at a similar level in both treatments and are very close to the equitable wage of 10 . However, they fall substantially almost immediately in treatment NMF and even faster in treatment MF with a minimum wage in place. In spite of the fact that the minimum wage provides a lower bound for the wages in treatment MF, the average wage is lower than in treatment NMF in all but two of the first 20 periods. This holds even though the wages fall below 3 in several of the groups of treatment NMF. Similarly, as displayed in Table 1, the average wage over all 20 periods in the first part of the experiment is higher in treatment NMF than in treatment MF.

To understand the wage dynamics better, we take a closer look at the development across periods. We run random-effects panel data regressions, using each independent market (with two sellers) as an independent observation

$$
\text { wage }_{i t}=\alpha * M F_{i t}+\beta * \text { Period }_{i t}+\gamma *(M F \times \text { Period })_{i t}+\delta_{i}+\varepsilon_{i t}
$$

\footnotetext{
${ }^{9}$ We observe some cases where it appears that a participant in the role of the firm confused wage and price. One player did this consistently for a number of periods and after the experiment admitted doing so. For other participants we infer this, because for one period they reverse a price-wage pattern that they have chosen before and afterwards. We generally excluded these observations from the analysis of price and wage choices. Including them, however, neither affects any of our results qualitatively nor the significance of any of the treatment differences.
} 


\begin{tabular}{ccc}
\hline \hline & Periods 1-20 & Periods 21-40 \\
\hline NMF & 6.57 & 6.06 \\
MF & 5.03 & 2.72 \\
\hline
\end{tabular}

Table 1: Average wages by treatment and phase (not weighted by quantities purchased) where $M F$ is a dummy that equals 1 for treatment MF and 0 for treatment NMF and $M F \times$ period is the interaction effect of this dummy and the period. ${ }^{10}$ Figure 1 suggests that the wage initially falls faster in MF. To capture these different developments, we run the regressions for the whole first half of the experiment (periods 1-20), for periods 1-10 only and for periods 1-5 only. The results are in Table 2 . When considering only the first five periods, there is a much faster decline of wages in MF than in NMF, and the decline in NMF is not significant. ${ }^{11}$ Considering periods 1 to 10 suggests wages do not decline at a significantly different rate. Taking the first 20 periods into account, due to the steep initial drop and relatively flat development afterwards, the regression suggests that wages in MF are initially lower but decline less rapidly than in NMF. To summarize, in the treatment with a minimum wage wages decline rapidly, and the decline then comes almost to a stop. Without a minimum wage, the decline is slower and more stable.

We observe that wages decrease in both treatments in early periods. This can be

\footnotetext{
${ }^{10}$ Fixed effects models yield similar results, and the MF dummy is dropped since it does not vary within independent observations.

${ }^{11}$ Using a Mann-Whitney test, the difference between wages in both treatments for the first twenty, first ten or first five periods misses to be significantly different from zero $(p>0.1$, marginally in the case of the first ten periods). For all Mann-Whitney tests in this paper, we use group averages to ensure independence of the data.
} 


\begin{tabular}{cccccc}
\hline \hline & Periods 1-20 & Periods 1-10 & Periods 1-5 & Periods 21-40 & Periods 21-30 \\
MF & $-2.6756^{* *}$ & -2.2398 & 0.1765 & $-2.8038^{* *}$ & $-3.2713^{* * *}$ \\
& $(1.0783)$ & $(1.5357)$ & $(2.0731)$ & $(1.2102)$ & $(1.2539)$ \\
Period & $-0.2701^{* * *}$ & $-0.5156^{* * *}$ & -0.4292 & $0.0546^{* * *}$ & -0.0015 \\
& $(0.0298)$ & $(0.0977)$ & $(0.3018)$ & $(0.0162)$ & $(0.0453)$ \\
MF $\times$ Period & $0.0992^{* *}$ & -0.0232 & $-0.9623^{* *}$ & $-0.0519^{* *}$ & 0.0436 \\
Constant & $(0.0420)$ & $(0.1379)$ & $(0.4271)$ & $(0.0228)$ & $(0.0640)$ \\
& $9.5009^{* * *}$ & $10.871^{* * *}$ & $10.7495^{* * *}$ & $5.4899^{* * *}$ & $5.7755^{* * *}$ \\
\hline \# Observations & $(0.7637)$ & $(1.0904)$ & $(1.4718)$ & $(0.8559)$ & $(0.8870)$ \\
\hline$R^{2}$ & 0.1189 & 0.1317 & 0.1262 & 0.2245 & 0.1952 \\
\hline \hline
\end{tabular}

Table 2: Coefficients for regression of the wage depending on the treatment, the period as well as the interaction between both. Standard errors in parantheses, *: significant at $p<0.1,{ }^{* *}$ : significant at $p<0.05,{ }^{* * *}$ : significant at $p<0.01$. Note that for the second part of the experiment, the time variable is taken as period -20 in order to capture the treatment difference at the start of the second half in the variable MF. 
interpreted as some firms initially expecting consumers to be more concerned with fair wages than they actually are. When they discover that consumers frequently are not concerned with wages but only with prices, they lower the wage and the price. Since consumer behavior is less driven by wages in MF (see Section 3.3), wages decline even faster than in NMF. In addition, firms might hold overly optimistic beliefs about the fairness of the competing firm. When they learn that the other firm does not pay a high wage (in combination with a high price), they reduce their wage and price as well. An alternative explanation would be that relatively high initial wages are driven by confusion and firms learn over the first periods that paying positive wages only lowers their profits. This does not explain, however, why wages initially decline faster in MF, and it is also not in line with rising wages in the second part of treatment NMF as described below.

Observation 1: Average wage offers in the first part of the experiment (periods 1-20) are higher in the treatment without a minimum wage (NMF) than in the treatment with a minimum wage (MF). In both treatments wages decline over the first 20 periods, and they decline more rapidly in the first periods of the treatment with a minimum wage (MF) than without a minimum wage (NMF).

Now focus on the second part of the experiment (periods 21-40) where a minimum wage is introduced in treatment NMF and the minimum wage is removed in treatment MF. A Mann-Whitney test yields a significant difference in wages between the two treatments in the second half of the experiment $(p<0.05)$, with higher wages in treatment NMF with a minimum wage. The minimum wage in treatment NMF stabilizes the wages significantly above the level in MF and thus has a positive effect on the workers' earnings. The panel 
regressions reported in the last two columns of Table 2 reveal the temporal aspect of this difference: Wages are significantly lower in MF than in NMF already in period 21. Moreover, there is a slight, but significant increase over time in NMF, but not in MF. ${ }^{12}$ Interestingly, as shown in the last column, there is no significant time trend in periods 21-30, so the upward trend materializes primarily in the last ten periods. This can also be seen in Figure 1. Thus, the difference established between the treatments is increasing and would hence be likely to persist over more periods of play.

To explain these results, notice that wages have decreased sharply in both treatments until period 20, i.e. by the end of the first part of the experiment. In period 21, there is not much fair behavior left in both treatments. Thus, the minimum wage is often binding and thus has a positive effect on wages. The minimum wage, however, also affects behavior when it is not binding. This becomes evident in the upward movement of wages in the last periods of treatment NMF where a minimum wage is in place. Here, the minimum wage might strengthen fairness concerns of consumers who have experienced an unregulated market first in which they already developed a sense of responsibility for the worker.

Observation 2: In the second part of the experiment (periods 21-40), wages are on average higher in treatment NMF with a minimum wage than in treatment MF without a minimum wage. Moreover, this difference is increasing over time.

What is the overall effect of a minimum wage, taking together both parts of the experiment? A panel regression yields a highly significant difference between wages $(p<0.001)$, such that there is an overall positive effect of the minimum wage. Thus, the lower wages in

\footnotetext{
${ }^{12}$ Note that the interaction term MF $\times$ Period almost completely cancels the coefficient of Period.
} 
the first part with a minimum wage are overcompensated by the higher wages in the second part with a minimum wage.

Finally, which treatment, NMF or MF, leads to higher wages? Or, in other words, what is the effect of ordering the two regimes in one way or the other on wage offers? Based on a Mann-Whitney test, we find that wages are significantly higher in treatment NMF than in treatment MF $(p<0.05)$. This is due to the initially lower wage in MF than in NMF and the higher wage in NMF than in MF in the second part of the experiment where the minimum wage is often binding.

We further make the important observation that the groups in treatment NMF are very heterogenous both with respect to the wages in the first 20 periods as well as in their reaction to the introduction of a minimum wage. We calculate group averages across blocks of five periods and consider in particular the last block in the first part (periods 16-20) and in the second part (periods 36-40), see Table 3. In two of the groups, the average wage is close to the equitable wage of 10 . One of them $(\# 1)$ is unaffected by the introduction of the minimum wage. In the other group (\#9) the wage increases even further. It appears that these groups have established a norm for a fair wage where the introduction of a (substantially lower) minimum wage has little effect or even strengthens the norm. Two groups $(\# 4, \# 10)$ have wages substantially above the level of the minimum wage but substantially below the equitable wage by the end of the first part. In both groups, the introduction of a minimum wage leads to a decline of wages, but it increases again towards the end of the second part and ends substantially above the minimum wage. It appears that consumers in these groups attempt to establish fair wages but that there is no well-established norm and that the introduction of the minimum wage provides a 


\begin{tabular}{|c|c|c|c|c|}
\hline NMF & & & & \\
\hline Group & Periods 1-20 & Periods $16-20$ & Periods $21-40$ & Periods $36-40$ \\
\hline 1 & 10.03 & 9.8 & 10 & 10 \\
\hline 2 & 5.98 & 4.5 & 7.31 & 6.4 \\
\hline 3 & 3.36 & 0.3 & 3 & 3 \\
\hline 4 & 7 & 5.9 & 5 & 6.6 \\
\hline 5 & 4.78 & 1.75 & 3.53 & 3.6 \\
\hline 6 & 2.7 & 1.9 & 4.08 & 4.2 \\
\hline 7 & 8.11 & 4.3 & 6.3 & 8.3 \\
\hline 8 & 3.87 & 3.8 & 4.03 & 4.6 \\
\hline 9 & 13.16 & 10.4 & 13.38 & 15.1 \\
\hline 10 & 7.1 & 7.4 & 4.05 & 5.4 \\
\hline Total & 6.57 & 5.07 & 6.06 & 6.72 \\
\hline MF & & & & \\
\hline 1 & 6.18 & 5.1 & 4.68 & 5.7 \\
\hline 2 & 5.4 & 3.2 & 3 & 3.4 \\
\hline 3 & 6.18 & 6.11 & 4.88 & 4.7 \\
\hline 4 & 4.72 & 3 & 0.28 & 0.7 \\
\hline 5 & 6 & 3 & 1.18 & 0.7 \\
\hline 6 & 3.16 & 3 & 0.9 & 1 \\
\hline 7 & 5.54 & 6.5 & 5.38 & 3.6 \\
\hline 8 & 5.26 & 5 & 2.94 & 1.9 \\
\hline 9 & 3.82 & 3.7 & 1.03 & 1.67 \\
\hline 10 & 3.93 & 3.1 & 2.9 & 3.7 \\
\hline Total & 5.03 & 4.19 & 2.72 & 2.72 \\
\hline
\end{tabular}

Table 3: Average wages (not weighted by quantities purchased and excluding obvious errors by firms) for treatments NMF and MF for the first part and the second part as well as for the last five periods in each part. 
temporary focal point for firms to set a low wage. In the long run relatively fairer wages get established again. In two groups $(\# 2, \# 7)$ wages are slightly above the level of the minimum wage at the end of the first part, but increase substantially after the introduction of the minimum wage. In these groups, the minimum wage appears to help establish a norm for a fair wage that is substantially higher than the minimum wage. Notice that in this case the minimum wage seems to affect behavior even though it is not binding. Finally, in the last four groups $(\# 3, \# 5, \# 6, \# 8)$ the wage has fallen to below or near the minimum wage level by the end of the first part. Thus, the minimum wage becomes binding (or nearly binding).

To summarize, treatment NMF suggests that introducing a minimum wage in groups that have reached a stable wage level does not affect the subjects' behavior. However, the minimum wage can, at least temporarily, interfere with fair wage-setting in groups that are still somewhat less settled. On the other hand, the minimum wage can help establish a fair wage level or simply become binding in groups that have not paid fair wages so far. Thus the effects of introducing a minimum wage in markets that have been running for a while appears to be mostly neutral, occasionally beneficial and only rarely problematic.

In stark contrast to treatment NMF, the groups in treatment MF are more homogeneous, with six groups exactly at the minimum wage or close to it and none with an average above 7 in the last periods of the first part, see Table 3 . Thus it appears that if a minimum wage is in place before the group can develop its own standard of a fair wage, this frequently leads to crowding out of fairness. The reaction to the abolishment of the minimum wage is, however, heterogenous. In four groups (\#4,\#5,\#6,\#9), the wage deteriorates further, suggesting that in these groups fairness considerations are almost irrelevant and have perhaps been 
completely undermined by the minimum wage. In the other two groups $(\# 2, \# 10)$ the average wage is virtually unaffected, suggesting that the minimum wage was established as a norm for an acceptable wage in these groups. This indicates that fairness concerns play some role in these groups. Among the remaining four groups where average wages are substantially higher than the minimum wage in the first part, we observe a substantial decline in the average wage in one group (\#8), with even lower wages in the last five periods, while in the other three groups $(\# 1, \# 3, \# 7)$, there is only a slight decrease in wages from the first to the second part and no clear pattern in the last five periods.

We note that in all 10 groups in treatment MF the average wage in the second part is lower than in the first part (though this is not always true for the last five periods in each part). This is in clear contrast to Treatment NMF, where the average wage is higher in the second than in the first part for four groups. To summarize, abolishing a minimum wage never has a positive effect. It has no effect on some groups that have apparently settled at a wage near or above the minimum wage, but often leads to a deterioration of wages if the minimum wage has been binding.

\subsection{Prices}

How do firms choose prices and wages, and what is the relationship between the two? A firm receives the price $p$ and has to pay the wage $w$ per unit of output sold. If a firm increases or decreases its price, it can hold its profit constant by moving the wage up or down by the same amount. For example, when competition forces the firm to set lower prices, it could secure itself a constant profit by lowering the wage. Alternatively, firms might look at their two choices separately. This aspect of firm strategy can be analyzed by looking at 


\begin{tabular}{ccc}
\hline \hline & Periods 1-20 & Periods 21-40 \\
\hline NMF & 0.7776 & 0.7012 \\
MF & 0.4664 & 0.4626 \\
\hline
\end{tabular}

Table 4: Correlations between wages and prices. All coefficients are significant at $p<0.05$.

the correlation between price and wage for both firms. We find a clear correlation between wages and prices for all parts of the experiment. Considering all decisions of firms in all periods, the correlation coefficient is $0.6319(p<0.05)$. Table 4 shows that the correlations are strong and significant for each of the different parts of the experiment. ${ }^{13}$ The coefficients are slightly lower in treatment MF with a minimum wage first.

As can be taken from Table 5, in the first part of the experiment (periods 1-20) prices are higher in NMF than in MF. The same is true for the second part of the experiment where prices in NMF exceed prices in MF. According to Mann-Whitney tests, the differences are not significant in either part or across the whole experiment $(p>0.1)$. Random-effects panel data regressions as above, however, show that in the first part, prices in MF are significantly lower $(p<0.05)$, and decrease over time in both treatments $(p<0.001)$ with no significant difference between time trends in the treatments. Similarly in the second part, prices are overall lower in $\operatorname{MF}(p<0.1)$ and decrease over time in both treatments $(p<0.05)$ with no significant difference in time trends between treatments.

Observation 3: (i) Price and wage choices by firms are strongly positively correlated. (ii) Prices are higher in both parts of the treatment without a minimum wage first (NMF)

\footnotetext{
${ }^{13}$ As the test does not take into account the dependence of observations, the significance levels should be interpreted with caution.
} 


\begin{tabular}{ccc}
\hline \hline & Periods 1-20 & Periods 21-40 \\
\hline NMF & 14.89 & 13.31 \\
MF & 12.12 & 9.76 \\
\hline
\end{tabular}

Table 5: Average prices by treatment and part of the experiment (not weighted by quantities purchased)

than in the treatment with a minimum wage first (MF).

Given the close correlation between wages and prices, the results on prices mirror the results from the section on wages. Thus, a minimum wage typically increases prices if it increases the wages, but it can also decrease prices when it crowds out fairness and thereby reduces wage payments. We observe that the correlation between prices and wages is lower in treatment MF than in treatment NMF in both parts of the experiment. This suggests that the subjects view the choices of wage and price more as separate decisions when a minimum wage is in place from the beginning of the experiment on.

Since both wages and prices are generally lower in MF than in NMF, the question arises whether firms are better off if wages are lower or whether the benefit goes exclusively to consumers in the form of lower prices. Obviously the lower wages in MF translate into lower earnings for workers and the lower prices into a higher rent for consumers. Table 6 shows the firm profits, worker earnings and consumer surplus by treatment for both parts of the experiment. Five results are noteworthy. First, in treatment NMF, the distribution of surplus does not differ much between both parts of the experiment. That is, neither do workers on average suffer or benefit from the introduction of a minimum wage, nor does it affect the average firm or consumer substantially. Second, firms benefit and workers 


\begin{tabular}{ccccccc}
\hline \hline & \multicolumn{2}{c}{ Periods 1-20 } & \multicolumn{3}{c}{ Periods 21-40 } \\
\hline & firm & worker & consumer & firm & worker & consumer \\
\hline NMF & 28.31 & 31.21 & 108.84 & 30.43 & 29.12 & 118.65 \\
MF & 15.26 & 25.68 & 156.24 & 26.34 & 12.8 & 166.09 \\
\hline
\end{tabular}

Table 6: Average payoffs per period by treatment and phase. From left to right each row shows average firm profit, average worker earnings and average consumer surplus.

suffer from the abolition of the minimum wage in the second part of MF. Third, in both treatments the bulk of the surplus is captured by consumers. Fourth, consumers capture an even larger share of the total surplus in MF (about two thirds) than in NMF (about half). ${ }^{14}$ Fifth, firms do not profit from the lower wages in both parts of MF compared to NMF. This suggests that the different price and wage patterns between treatments are driven by differences in consumer behavior and not, for example, by collusion of firms on low wages. ${ }^{15}$ We address the consumer behavior in the next subsection.

\subsection{Consumer behavior}

Finally, let us focus on the choices of consumers in both treatments. The most striking difference is found with respect to the willingness of consumers to pay a higher price if

\footnotetext{
${ }^{14}$ Remember that there are two firms and two workers, but only one consumer in each market. Thus when a consumer captures half of the total surplus, he earns four times as much as the average of the other market participants and eight times as much if he captures two thirds of the total.

${ }^{15}$ The argument underlying this alternative explanation would be that a minimum wage provides a focal point for collusion of firms on low wages. This explanation is not supported. Similarly, related experiments do not provide evidence that price floors (Dufwenberg et al., 2006) and price ceilings (Engelmann and Müller, 2007) help firms to collude by providing a focal point.
} 


\begin{tabular}{ccc}
\hline \hline & Periods 1-20 & Periods 21-40 \\
\hline NMF & $25.5 \%$ & $25.4 \%$ \\
MF & $0 \%$ & $21.3 \%$ \\
\hline
\end{tabular}

Table 7: Percentage of consumers buying more units from the firm with the higher wage and price

the respective firm pays a higher wage. In the first half of treatment NMF, consumers buy more units from the firm with a higher wage and higher price than from the firm with the lower wage and price in $25.5 \%$ of cases where this is possible and seven of ten consumers do this at least once. ${ }^{16}$ In stark contrast to this result, consumers never do this in the first part of treatment MF. This difference is highly significant (MW-test, $p<0.01$ ), which suggests that fairness concerns of consumers are crowed out by the minimum wage. Consumer behavior in the second part is very similar to consumer behavior in the first part of NMF (see Table 7) and far from being different between treatments (MW-test, $p>0.8$ ).

Observation 4: (i) In the first part of the experiment, consumers never buy from the firm with the higher price and the higher wage in the treatment with a minimum wage (MF) while they do so significantly more often if there is no minimum wage (NMF). (ii) In the second part of the experiment, consumer behavior is statistically indistinguishable in this respect between treatments $N M F$ and $M F$.

\footnotetext{
${ }^{16}$ In many cases, we cannot assess whether the consumer would be willing to pay a higher price for a higher wage because the firms set equal prices, or equal wages, or the firm with the higher wage charges the lower price. Out of 200 choices made by consumers in the first part of the experiment, there were 97 cases in Treatment NMF and 64 in Treatment MF with a high-wage high-price firm.
} 
It appears that consumers who are initially willing to buy from a high-wage high-price firm are not discouraged to do so by the introduction of a minimum wage. On the other hand, consumers starting the experiment with a minimum wage do not choose the highprice high-wage firm, but they start to do so after the abolition of the minimum wage. This suggests that they initially consider workers to be sufficiently protected by the minimum wage so that they do not have to buy from firms with high wages in order to support workers. After the abolition of the minimum wage, however, some consumers are willing to pay a higher price, apparently in order to prevent a further decline of wages.

In addition to considering whether consumers buy more at the high-price high-wage firm, we consider how consumers spread their purchases across firms in general. Remember that they can buy up to 10 units per period and can spread these units as they like between the two firms. In MF, consumers actually buy 10 units in $94 \%$ of the cases, in NMF this is the case in only $81 \%$. Overall, the only purchasing patterns occurring frequently are either to buy 10 units at one firm (71\% in MF and 53\% in NMF) or to buy equal numbers of units at both firms (16\% in MF and $24 \%$ in NMF, including buying nothing at both in $1 \%$ and $2 \%$ of the cases, respectively). Of the cases where consumers spread purchases equally, the vast majority $(74 \%)$ occurs when prices are equal, while this can almost never be observed when prices differ by more than 3 points. Spreading purchases equally can be seen as another indication of fairness concerns, since the consumer equalizes payoffs between firms (and between workers in case wages are equal as well). It is in line with the previous results of the paper that consumers more frequently buy an equal number of units at both firms in NMF than in MF, indicating that in this treatment they care more about fairness. Similarly, buying less than 10 units can be a signal that consumers consider prices 
as too high or wages as too low at both firms which occurs more frequently in NMF than in MF.

Figure 2 shows the frequency with which consumers buy a different number of units at the two firms depending on the difference between the price of the firm where they buy more $\left(p_{m}\right)$ and the price of the firm where they buy less $\left(p_{l}\right)$. While consumers overwhelmingly

buy more units at the (weakly) cheaper firm $\left(p_{m} \leq p_{l}\right)$, we also see that they buy far more frequently at the more expensive firm in NMF than in MF, in particular in the first part. In MF, we do not observe any case where consumers buy more at a firm with a substantially higher price $\left(p_{m}>p_{l}+3\right)$. Furthermore, in the first part of MF there is only one case where a consumer buys more at a moderately more expensive firm $\left(p_{l}<p_{m} \leq p_{l}+3\right)$. This indicates clearly that in the first part of MF the primary criterion for the consumers is the price, which is not exclusively true in the second part and much less so in NMF.

\section{Discussion and Concluding Remarks}

We have studied the effects of a minimum wage in a simple market experiment with two sellers, a monopsonistic buyer, and passive workers. The latter two features as well as fixed matching and low equilibrium earnings for the worker are chosen in order to maximize the likelihood that the consumers care about the workers' well-being by buying from the firm that pays a higher wage. We can then study the interaction of such fairness concerns with a minimum wage.

We observe that there is a lot of heterogeneity among consumers, ranging from purely selfish behavior to some consumers who enforce an equal distribution of payoffs. Interestingly, the latter behavior is not observed if a minimum wage is in place already at the 


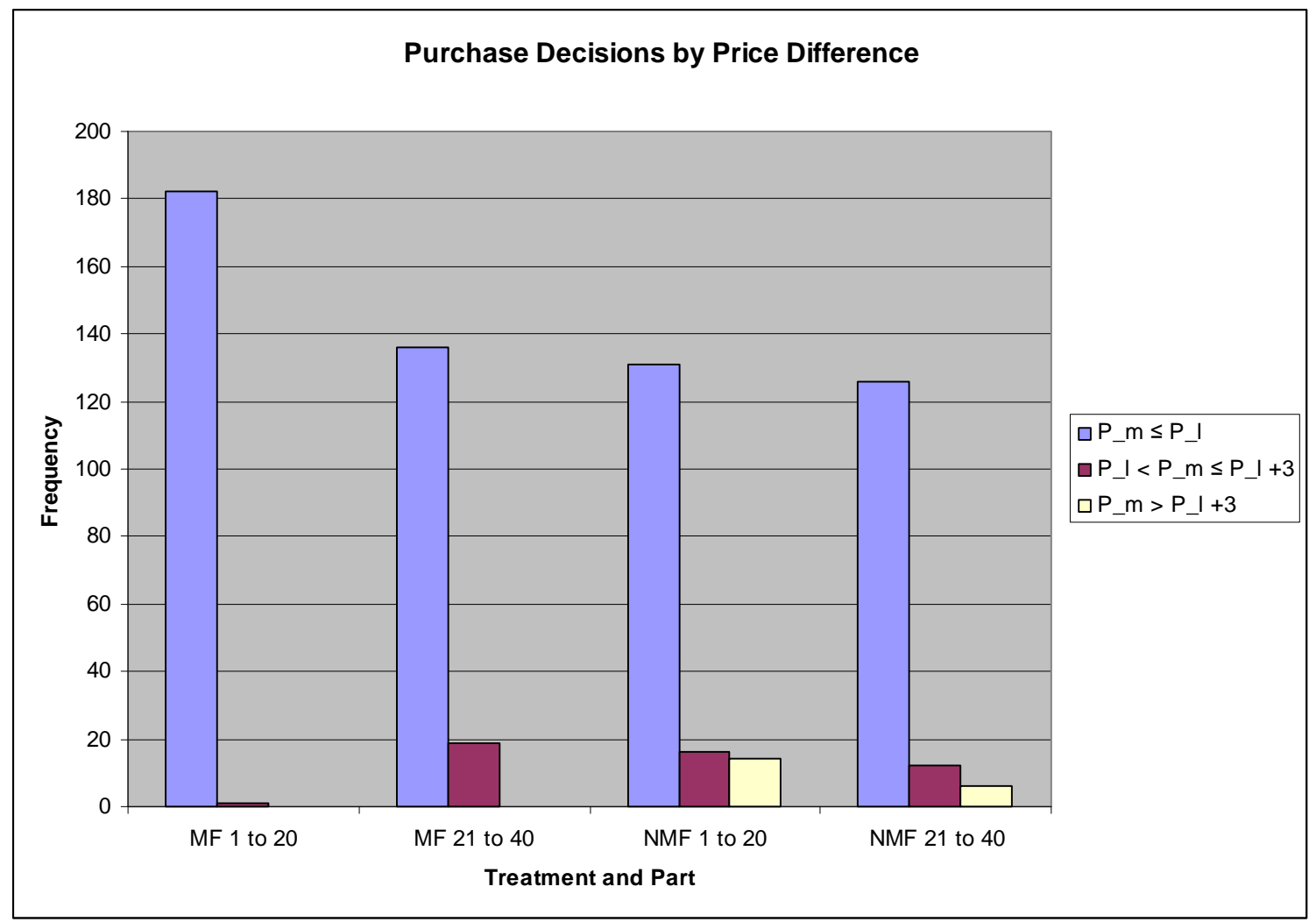

Figure 2: Frequency of consumers buying more at one firm depending on the difference between the price where the consumer buys more $\left(p_{m}\right)$ and the price where the consumer buys less $\left(p_{l}\right)$ by treatment and phase. The left bar captures the cases where the consumer buys more at the (weakly) cheaper firm $\left(p_{m} \leq p_{l}\right)$, the second bar the cases where the consumer buys more at a moderately more expensive firm $\left(p_{l}<p_{m} \leq p_{l}+3\right)$ and the right bar the cases where the consumer buys at a substantially more expensive firm $\left(p_{m}>p_{l}+3\right)$. 
beginning of the experiment. This suggests that the minimum wage signals to consumers that the workers' well-being is sufficiently taken care off such that there is no need to pay a high price to a firm that pays fair wages. Firms seem to learn this as the wages decline faster in the treatment with a minimum wage in the first part of the experiment than in the treatment without a minimum wage at first. This observation supports our hypothesis that legal regulations can lead to crowding out of concerns for fairness.

In contrast to the detrimental effects of a minimum wage at an early stage of the experiment, a later introduction of the minimum wage has a positive effect on the average wage level. The reason is that markets where relatively fair wages have been established are hardly affected by a minimum wage while it is binding in other markets with rather low wages. Therefore, the overall effect of a minimum wage seems to depend on existing standards of fairness in the market. In a mature state where some consumers have clearly established standards for ethical behavior and firms can thus profit from paying a fair wage, these standards are not undermined by the introduction of regulations. On the other hand, if the regulation is introduced at an early stage, it is harder for firms to establish a reputation for ethical behavior for two reasons. First, it becomes more difficult to distinguish themselves from firms that only satisfy the legal minimum in the presence of a minimum wage. Second, consumers might believe that the issue is sufficiently taken care off by the regulation. ${ }^{17}$

Naturally, one should take great care in deriving policy implications from a highly

\footnotetext{
${ }^{17}$ In the framework of our experiment this means that a consumer who has established that she considers $w=10$ a fair wage is not very likely to change her opinion by the introduction of a minimum wage of 3 , whereas if she is confronted with an initial minimum wage of 3 , she might consider this as sufficient.
} 
stylized experimental setting such as ours. Our experiment primarily serves as an existence proof for the possibility that the regulation of "ethical" behavior can undermine the reputation gains that firms obtain from such ethical behavior. Such effects can, at least temporarily, lead to worse outcomes than without the regulation. Furthermore, it shows that the overall effect of a regulation can depend on the maturity of the market and established standards of behavior. Our results suggest that the most effective way to attain ethical behavior by firms would be to first let the market operate without any regulations in order to let some firms establish a reputation for ethical behavior. If the overall result is not satisfactory, regulation can be introduced to improve the behavior of the remaining firms, without threatening the reputation of those firms who are already fulfilling or overfulfilling the desired standard of behavior. Furthermore, our results suggest that removing the regulation can lead to poor outcomes for the workers. Possibly, the removal of the minimum wage signals that there is no need for a higher wage (any more).

Several limitations of our study should be mentioned. They leave ample room for more research on the topic at hand. One of the issues where our experiment deviates from most real markets is the presence of a monopsonistic buyer. This design element maximizes the power of the buyer to influence firm behavior. If there are many buyers, free-rider and coordination problems must be overcome because an individual buyer's influence on the behavior of the firms can be negligible while her own costs of buying from an "ethical" firm can be substantial. Thus, our study is not meant to provide a realistic measure of the amount of fairness per se, but it is designed to investigate the interaction between fairness concerns of consumers and legal regulations. 
Another feature of our experiment is Bertrand competition between firms. Firms have no market power and therefore little room for fairness. We chose Bertrand competition to focus our study on consumers and their concerns for fairness. With market power, firms could in principle pay for fair behavior even if the consumers do not value it. It remains to be investigated how the firms' willingness to pay for fairness is affected by the form of competition, legal institutions, etc.

\section{References}

Brandts, J. and Charness, G. (2004). Do Labour Market Conditions Affect Gift Exchange? Some Experimental Evidence. Economic Journal, 114, 684-708.

Card, D. (1992). Do Minimum Wages reduce Employment? A Case Study of California 1987-89. Industrial and Labor Relations Review, 46(1), 38-54.

Card, D. and Krueger, A. (1994). Minimum Wages and Employment: A Case Study of the Fast-Food Industry in New Jersey and Pennsylvania.American Economic Review, $84(4), 772-793$.

Card, D. and Krueger, A. (1995). Myth and Measurement. The New Economics of the Minimum Wage. Princeton University Press, Princeton, New Jersey.

Charness, G. and Rabin, M. (2002). Understanding Social Preferences with Simple Tests. Quarterly Journal of Economics 117(3), 817-869. 
Dickens, R., Machin, S., and Manning, A. (1999). The Effects of Minimum Wages on Employment: Theory and Evidence from Britain. Journal of Labor Economics 17(1), $1-23$.

Dufwenberg, M, Gneezy, U., Goeree, J.K., and Nagel. R. (2006). Price Floors and Competition. Economic Theory 33, 211-224.

Engelmann, D. and Fischbacher, U. (2003). Indirect Reciprocity and Strategic Reputation Building in an Experimental Helping Game. CERGE-EI working paper No. 215.

Engelmann, D. and Müller, W. (2007). In Search of Collusive Effects of Price Ceilings Evidence from the Laboratory. mimeo, Royal Holloway, University of London.

Engelmann, D. and Strobel, M. (2004). Inequality Aversion, Efficiency, and Maximin Preferences in Simple Distribution Experiments. American Economic Review, 94(4), $857-869$.

Falk, A., Fehr, E., and Zehnder, C. (2006). Fairness Perceptions and Reservation Wages - The Behavioral Effects of Minimum Wage Laws. Quarterly Journal of Economics, $121(4), 1347-1381$.

Falk, A. and Kosfeld, M. (2006). The Hidden Costs of Control, American Economic Review, 96 (5), 1611-1630.

Fehr, E., and Fischbacher, U. (2004). Third-Party Punishment and Social Norms. Evolution and Human Behavior, 25, 63-87. 
Forsythe, R., Horowitz, J.L., Savin, N.E., and Sefton, M. (1994). Fairness in Simple Bargaining Experiments. Games and Economic Behavior, 6, 347-369.

Fischbacher, U., 2007. Zurich Toolbox for Ready-made Economic experiments. Experimental Economics, 10(2), 171-178.

Freeman, R.B. (1996). The Wage as a Redistributive Tool. Economic Journal, 106, 639649.

Frey, B.S. (1997). Not just for the Money. Edward Elgar, Cheltenham.

Frey, B.S. and Jegen, R. (2001). Motivation Crowding Theory. Journalf of Economic Surveys, 15, 589-611.

Gneezy, U. and Rustichini, A. (2000a). Pay Enough or Don't Pay at All. Quarterly Journal of Economics, 115(2), 791-810.

Gneezy, U. and Rustichini, A. (2000b). A Fine is a Price. Journal of Legal Studies, 29, $1-17$.

Güth, W. and van Damme, E. (1998). Information, Strategic Behavior and Fairness in Ultimatum Bargaining - An Experimental Study. J. Math. Psychology, 42, 227-247.

Güth, W., Schmidt, C., and Sutter, M. (2007). Bargaining Outside the Lab - A Newspaper Experiment of a Three Person-Ultimatum Game. Economic Journal, 117, 422-448.

Harrison, G.W. and Johnson, L.T. (2006). Identifying Altruism in the Laboratory. In: D. Davis (Ed.) Experiments in Fundraising and Charitable Contributions. Research in Experimental Economics, Volume 11. JAI Press, Greenwich, Conneticut. 
Katz, L. and Krueger, A. (1992). The Effect of the Minimum Wage on the Fast Food Industry. Industrial and Labor Relations Review, 46(1), 6-21.

Kritikos, A. and Bolle, F. (2001). Distributional Concerns: Equity- or Efficiency-oriented? Economics Letters, 73, 333-338.

Nowak, M.A. and Sigmund, K. (1998). Evolution of Indirect Reciprocity by Image Scoring. Nature 393, 573-577.

Ostrom, E. (2000). Collective Action and the Evolution of Social Norms. Journal of Economic Perspectives, 14(3), 137-158.

Roth, A.E. (1995). Bargaining Experiments, in J.H. Kagel and A.E. Roth (eds). The Handbook of Experimental Economics. Princeton University Press, Princeton.

Seinen, I. and Schram, A. (2006). Social Status and Group Norms: Indirect Reciprocity in a Helping Experiment. European Economic Review 50, 581-602. 


\section{SFB 649 Discussion Paper Series 2008}

For a complete list of Discussion Papers published by the SFB 649, please visit http://sfb649. wiwi. hu-berlin.de.

001 "Testing Monotonicity of Pricing Kernels" by Yuri Golubev, Wolfgang Härdle and Roman Timonfeev, January 2008.

002 "Adaptive pointwise estimation in time-inhomogeneous time-series models" by Pavel Cizek, Wolfgang Härdle and Vladimir Spokoiny, January 2008.

003 "The Bayesian Additive Classification Tree Applied to Credit Risk Modelling" by Junni L. Zhang and Wolfgang Härdle, January 2008.

004 "Independent Component Analysis Via Copula Techniques" by Ray-Bing Chen, Meihui Guo, Wolfgang Härdle and Shih-Feng Huang, January 2008.

005 "The Default Risk of Firms Examined with Smooth Support Vector Machines" by Wolfgang Härdle, Yuh-Jye Lee, Dorothea Schäfer and Yi-Ren Yeh, January 2008.

006 "Value-at-Risk and Expected Shortfall when there is long range dependence" by Wolfgang Härdle and Julius Mungo, Januray 2008.

007 "A Consistent Nonparametric Test for Causality in Quantile" by Kiho Jeong and Wolfgang Härdle, January 2008.

008 "Do Legal Standards Affect Ethical Concerns of Consumers?" by Dirk Engelmann and Dorothea Kübler, January 2008. 